\title{
PERANCANGAN SISTEM ANTRIAN PENDAFTARAN MAHASISWA BERBASIS KOMPUTER
}

\author{
Linda Wijayanti ${ }^{1}$, Surya Abadi $^{2}$
}

${ }^{1,2}$ Program Studi Teknik Elektro, Fakultas Teknik, Universitas Katolik Indonesia Atma Jaya e-mail: linda.wijayanti@atmajaya.ac.id ${ }^{1,}, \underline{\text { abadisurya.91@gmail.com }}{ }^{2}$

\begin{abstract}
Abstrak Hampir di setiap perguruan tinggi swasta, pendaftaran calon mahasiswa baru dilakukan setiap bulan, sehingga pada masa tertentu akan terjadi pelayanan mahasiswa lama yang bersamaan dengan calon mahasiswa baru. Untuk mengatasi kepadatan antrian yang panjang pada perguruan tinggi yang jumlah mahasiswanya ribuan, dibutuhkan sistem antrian yang handal dan terprogram secara otomatis. Sistem antrian yang dirancang dapat menggantikan petugas khusus untuk memberikan nomor antrian dan memanggil nomor antrian. Perangkat keras yang digunakan terdiri dari komputer, beberapa tombol tekan, mikrokontroler ATMega16, komunikasi RS- 232, dan konverter USB to serial. Masukan yang berasal dari tombol tekan diolah oleh komputer menggunakan program Borland Delphi. Komputer dihubungkan dengan mikrokontroler dan perangkat keras lainnya. Sistem antrian akan menghasilkan tampilan informasi nomor antrian dan nomor loket pada monitor LCD dan mengaktifkan file rekaman suara sebagai pemberitahuan melalui loudspeaker. Hasil pengujian sistem antrian telah berhasil memberikan informasi nomor antrian dan loket yang sesuai pada layar monitor maupun loudspeaker, serta telah berhasil mengatasi kepadatan antrian menjadi lebih teratur.
\end{abstract}

Kata Kunci: antrian, pendaftaran, loket, mikrokontroler ATMegal6, loudspeaker

\begin{abstract}
Almost in every private university, the enrollment of the prospective students is conducted every month, thus in some periods, there will be some overlapping with the enrollment for the current students. To overcome the extensive queue, especially at the university that has thousands of students, an automatically programmed and reliable queue system is needed. The queue system can substitute the designated person who distributes the ticket number and call the order. The hardware consists of computer, keypad, ATMegal6 microcontroller, RS-232 communication, and USB to serial converter. Input from the keypad is processed by the computer using Borland Delphi. Computer is connected with the microcontroller and the other hardware. The queue system will visualize the queue number and the directed counter number in the LCD monitor and play the recorded sound file through the loudspeaker. The test result from this queue system has successfully generated an information about the queue number and directed counter number in the monitor and loudspeaker, and also control the overwhelmed queue to be more organized.
\end{abstract}

Keywords : queue, enrollment, counter, microcontroller ATMega16, loudspeaker

\section{PENDAHULUAN}

Setiap perguruan tinggi memiliki unit yang menangani pendaftaran calon mahasiswa baru maupun mahasiswa lama. Pada umumnya sistem antrian pendaftaran dilakukan dengan berbaris dalam antrian menunggu sampai mendapatkan pelayanan atau ada petugas khusus untuk memberikan nomor dan memanggil nomor antrian. Untuk perguruan tinggi dengan jumlah calon mahasiswa baru dan mahasiswa lama yang besar, diperlukan suatu sistem untuk mendapatkan nomor antrian agar tidak terjadi barisan yang panjang untuk mendapatkan pelayanan. Mahasiswa lama maupun calon mahasiswa baru dapat mengambil nomor antrian dan memperoleh informasi berapa nomor yang masih ada dalam antrian sebelum mahasiswa tersebut mendapatkan pelayanan. Dengan adanya informasi yang ditampilkan pada layar monitor dan pemberitahuan melalui loudspeaker, maka 
mahasiswa maupun calon mahasiswa baru dapat melakukan kegiatan lain sebelum mendapatkan pelayanan dari unit pendaftaran.

Pada unit pendaftaran umumnya dipisahkan antara pendaftaran calon mahasiswa baru dan pelayanan untuk mahasiswa lama. Di Unika Atma Jaya pendaftaran calon mahasiswa baru telah dilakukan secara online, tetapi calon mahasiswa baru tetap harus menyerahkan berkas dan memperlihatkan berkas asli ke unit pendaftaran. Pendaftaran semester mahasiswa lama juga sudah dilakukan secara online, namun sering kali mahasiswa lama mempunyai masalah lain yang mengharuskan mereka datang ke unit pendaftaran.

Permasalahan ini memunculkan ide untuk membuat perancangan sistem antrian yang bekerja secara otomatis. Sistem ini tidak hanya dapat digunakan pada pendaftaran calon mahasiswa baru saja, tetapi juga untuk pelayanan akademik mahasiswa lama. Sistem ini memanfaatkan komputer, mikrokontroler dan perangkat elektronik, yang berguna untuk membuat sistem antrian menjadi otomatis dan efisien. Dengan sistem antrian yang otomatis ini akan menaikan tingkat kepuasan dan kenyamanan mahasiswa yang membutuhkan pelayanan di unit pendaftaran.

\section{TINJAUAN PUSTAKA}

Mikrokontroler adalah suatu chip yang terdiri atas unit pemroses, random access memory (RAM), read only memory (ROM), input/output (I/O), dan fasilitas pendukung lainnya [1]. Mikrokontroler yang digunakan adalah ATMega16, dengan spesifikasi sebagai berikut [2,3]:

1. Unit pemroses terdiri atas 32 register.

2. Saluran I/O sebanyak 32 buah.

3. Flash memory sebesar $16 \mathrm{~KB}$.

4. Static random access memory (SRAM) sebesar $512 \mathrm{~B}$.

5. Electrically erasable programmable read only memory (EEPROM) sebesar $512 \mathrm{~B}$.

6. Port USART untuk komunikasi serial.

RS-232 merupakan protokol standar yang mengatur komunikasi data secara serial. Pada sistem ini RS-232 dibutuhkan untuk mengonversikan level tegangan TTL menjadi level tegangan serial agar data dapat diterima dan diproses oleh komputer. Level tegangan serial untuk nilai logika 1 adalah antara $-3 \mathrm{~V}$ sampai $-25 \mathrm{~V}$, dan untuk logika 0 antara $3 \mathrm{~V}$ sampai $25 \mathrm{~V}$ [4]. Komunikasi ini bersifat full duplex yang berarti pengiriman data dan penerimaan data dapat dilakukan secara bersamaan karena jalur yang digunakan terpisah. Data disinkronisasikan menggunakan sebuah start bit dan sebuah stop bit. Sebuah frame data terdiri dari sebuah start bit, diikuti data 8 bit dan diakhiri dengan stop bit. Rangkaian antarmuka komunikasi serial RS 232 ini menggunakan IC MAX 232 [5]. 
Borland Delphi adalah suatu sarana pemrograman aplikasi berorientasi obyek dengan lingkungan kerja terpadu (Integrated Development Environment/IDE) yang menyediakan seluruh sarana yang diperlukan untuk merancang, membangun, mencoba, dan melacak kesalahan dalam pemrograman [6].

\section{METODE PENELITIAN}

Metodologi penelitian yang dilakukan untuk membuat rancang bangun sistem antrian adalah mengikuti tahapan sebagai berikut:

1. Melakukan analisis permasalahan antrian di unit pendaftaran dari narasumber yang kompeten dengan data yang akurat dan merancang kebutuhan sistem yang akan dibuat.

2. Melakukan studi pustaka dan sumber informasi komponen perangkat keras yang diperlukan untuk merealisasikan sistem antrian.

3. Membuat diagram blok perangkat keras dan diagram alir perangkat lunak sistem.

4. Merealisasikan penyediaan perangkat keras yang diperlukan.

5. Membuat kode program komputer dan mikrokontroler untuk menjalankan sistem yang dirancang.

6. Melakukan pengujian perangkat keras dan perangkat lunak serta pengujian secara menyeluruh pada sistem antrian yang dibuat.

\section{PERANCANGAN DIAGRAM BLOK SISTEM}

Pada sistem ini masukan berasal dari tombol tekan untuk mencetak nomor antrian dan tombol tekan petugas. Sedangkan keluaran sistem ini berupa suara panggilan di loudspeaker, tampilan di monitor LCD dan cetakan nomor antrian dari printer. PB1 adalah tombol masukan untuk pencetakan nomor antrian layanan mahasiswa lama, sedangkan PB2 tombol masukan untuk pencetakan nomor antrian pendaftaran mahasiswa baru. PB 3 - PB 10 adalah tombol petugas yang dapat diatur jenis pelayanannya sebagai petugas pendaftaran mahasiswa lama atau mahasiswa baru.

Jika terjadi penekanan tombol pada PB1 maupun PB2, mikrokontroler akan mengirimkan data ke komputer melalui komunikasi RS 232 dan konverter USB to serial. Selanjutnya data diolah untuk memberi perintah pencetakan struk nomor antrian kepada printer.

Petugas harus menekan tombol setiap kali selesai melayani mahasiswa. Jika ada petugas yang menekan tombol PB3 - PB10, mikrokontroler mengirimkan data ke komputer dengan proses seperti pencetakan nomor antrian. Data diolah oleh komputer untuk memberikan perintah memanggil nomor antrian pada monitor LCD dan mengaktifkan file suara melalui loudspeaker. Diagram blok sistem yang dirancang diperlihatkan pada Gambar 1. 


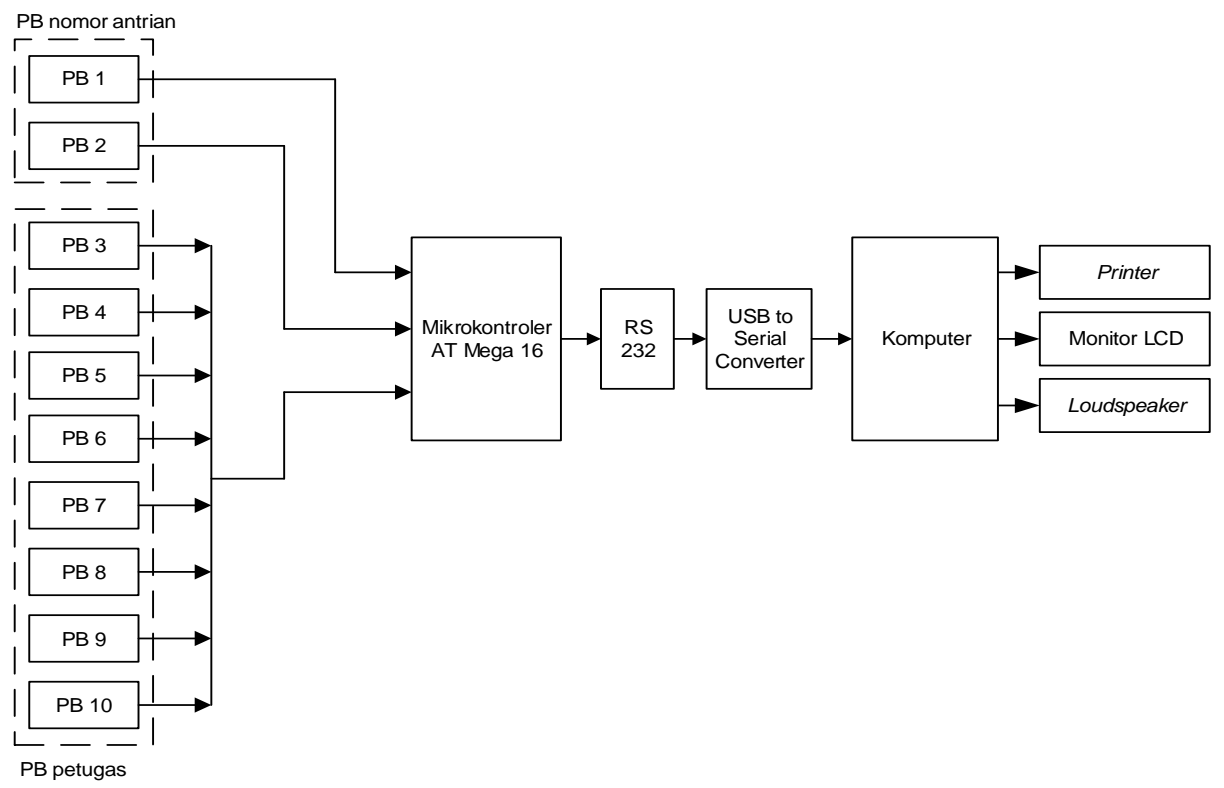

Gambar 1. Diagram blok sistem

\section{PERANCANGAN PERANGKAT KERAS}

Rangkaian catu daya menggunakan trafo yang berfungsi untuk menurunkan tegangan dari 220 Vac menjadi 12 Vac. Tegangan yang telah diturunkan disearahkan dengan menggunakan sebuah dioda bridge yang terdiri dari 4 buah dioda, sehingga dihasilkan tegangan dc. Kapasitor 1000uF dan $100 \mathrm{uF}$ dalam rangkaian berguna untuk memperkecil ripple sinyal keluaran. Rangkaian catu daya ini menggunakan regulator tegangan IC7805 agar menghasilkan tegangan keluaran linier 5 Vdc, sehingga sesuai untuk mencatu rangkaian mikrokontroler dan rangkaian RS 232. Rangkaian catu daya diperlihatkan pada Gambar 2.

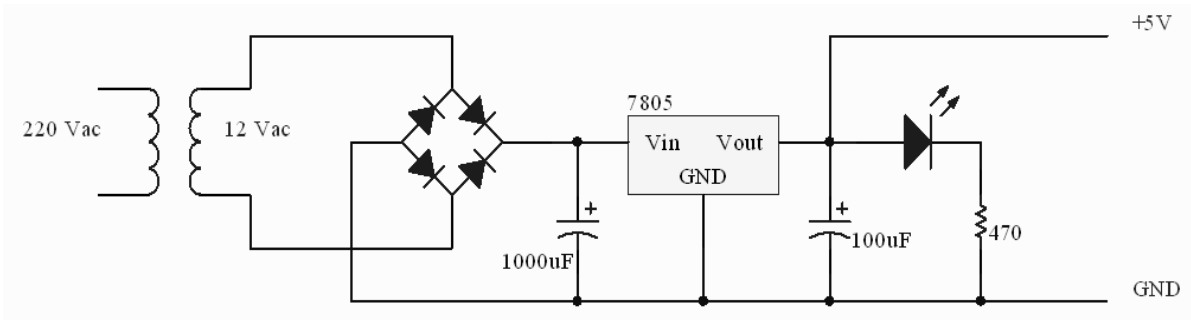

Gambar 2. Rangkaian catu daya

Rangkaian mikrokontroler berguna untuk mendeteksi masukan berupa penekanan tombol tekan. Masukan dari sistem berupa sepuluh buah tombol tekan terhubung dengan port I/0 pada mikrokontroler ATMega16 dan langsung terhubung ke ground, sehingga apabila ada penekanan pada salah satu tombol akan dihasilkan nilai logika '0'. Setiap tombol tekan (PB 1 - PB 10) akan mewakili data karakter tertentu. Hubungan antara tombol, kaki mikrokontroler dan data karakter yang dikirimkan diperlihatkan pada Tabel 1. 
Tabel 1. Hubungan antara tombol, kaki mikrokontroler dan data karakter

\begin{tabular}{|c|c|c|}
\hline Tombol & $\begin{array}{c}\text { Kaki } \\
\text { mikrokontroler }\end{array}$ & $\begin{array}{c}\text { Data } \\
\text { karakter }\end{array}$ \\
\hline PB 1 & PA0 & A \\
\hline PB 2 & PA1 & B \\
\hline PB 3 & PA2 & C \\
\hline PB 4 & PA3 & D \\
\hline PB 5 & PA4 & E \\
\hline PB 6 & PA5 & F \\
\hline PB 7 & PA6 & G \\
\hline PB 8 & PA7 & H \\
\hline PB 9 & PC7 & I \\
\hline PB 10 & PC6 & J \\
\hline
\end{tabular}

Jika terjadi penekanan pada tombol tertentu, maka mikrokontroler akan mengirimkan data karakter tertentu sesuai tombol yang ditekan. Pengiriman data dilakukan secara serial melalui USART yang terdapat pada mikrokontroler. Rangkaian keseluruhan sistem diperlihatkan pada Gambar 3.

Rangkaian komunikasi RS232 berfungsi untuk mengonversikan data serial yang diterima dari level tegangan mikrokontroler menjadi level tegangan RS232, untuk logika 1 antara -3V sampai -25V dan logika 0 antara 3V sampai 25V. Rangkaian ini menggunakan IC MAX 232. Keluaran dari IC MAX 232 dihubungkan dengan konverter USB to serial. Selanjutnya data berupa karakter dikirimkan ke komputer untuk diolah menggunakan perangkat lunak.

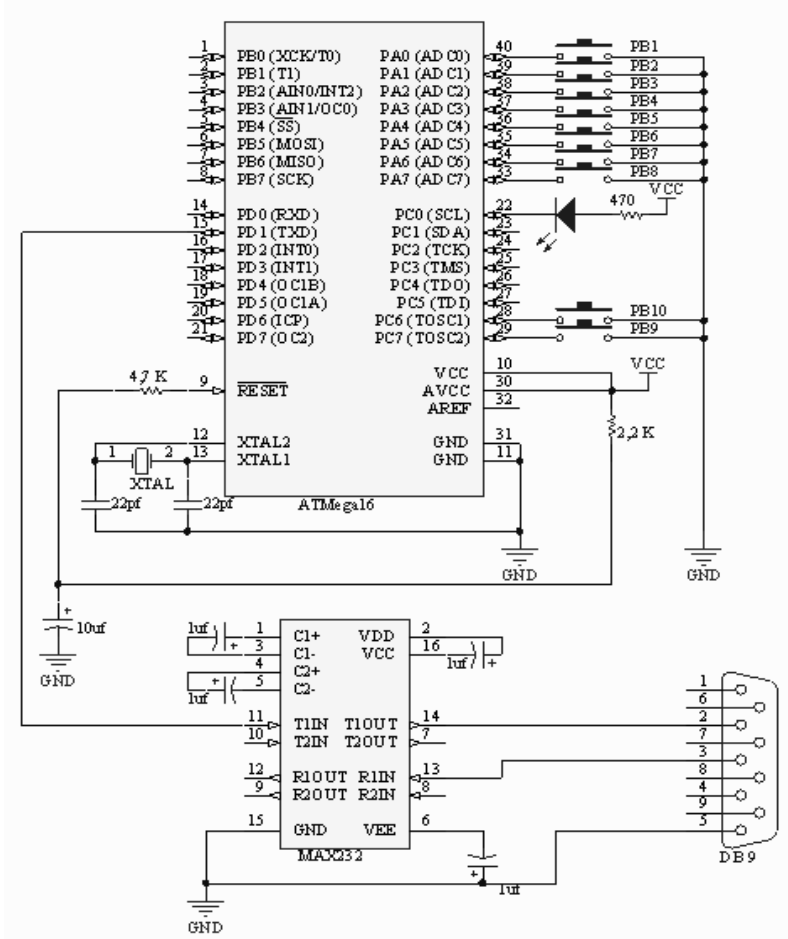

Gambar 3. Rangkaian sistem antrian keseluruhan 


\section{PERANCANGAN PERANGKAT LUNAK}

Perangkat lunak pada sistem ini berguna untuk mengolah masukan dari tombol tekan. Masukan dari mahasiswa merupakan perintah untuk mencetak struk nomor antrian menggunakan printer. Masukan dari petugas merupakan perintah memanggil nomor antrian. Tombol-tombol petugas dapat diatur oleh admin untuk dipakai pada pelayanan mahasiswa lama maupun mahasiswa baru, sehingga penggunaannya bisa lebih fleksibel. Diagram alir mikrokontroler diperlihatkan pada Gambar 4.

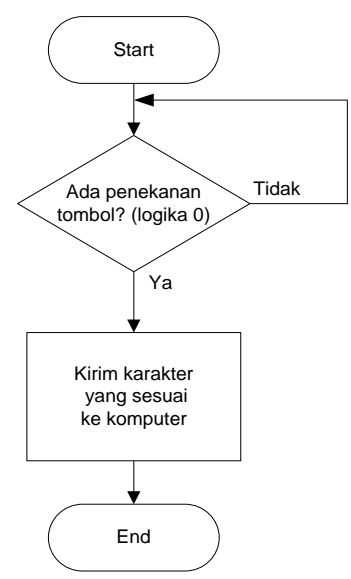

Gambar 4. Diagram alir mikrokontroler

Komponen ComPort, berguna untuk menerima data serial yang dikirimkan oleh mikrokontroler. Pada saat Button Start ditekan maka koneksi ComPort akan aktif.

Komponen Media Player digunakan untuk memainkan file audio berformat '.wav' sesuai dengan nomor antrian dan nomor loket. File audio berformat '.wav.' telah direkam dan disimpan di dalam harddisk. Suara yang direkam ke dalam file audio adalah "Nomor_antrian.wav", "Silakan_ke_loket. wav", “A.wav", "B.wav", “1.wav", “2.wav", ..., "11.wav”, "Belas.wav”, "Puluh.wav”, dan "Ratus.wav". Diagram alir untuk program pada komputer diperlihatkan pada Gambar 5. 


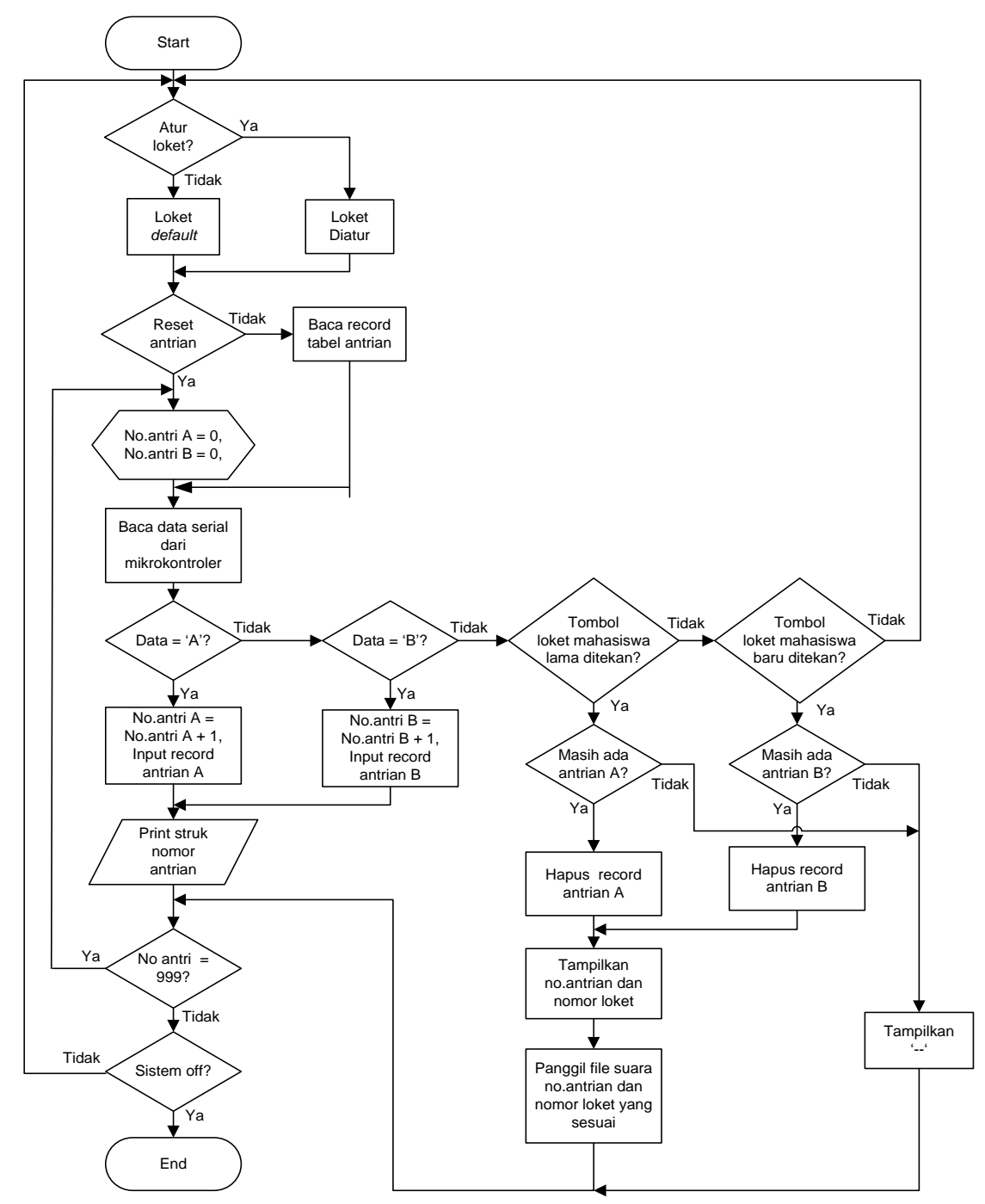

Gambar 5. Diagram alir komputer

\section{HASIL DAN PEMBAHASAN}

Makalah ini membahas rancang bangun perangkat elektronika pada sistem antrian di bagian pendaftaran mahasiswa di perguruan tinggi, dengan beberapa kriteria sebagai berikut:

1. Sistem dibuat berdasarkan kebutuhan di unit pendaftaran mahasiswa dan mudah dalam penggunaannya.

2. Pelayanan pendaftaran calon mahasiswa baru terpisah dengan pelayanan mahasiswa lama sehingga dibutuhkan dua sistem antrian secara terintegrasi.

3. Perancangan sistem antrian ini dapat digunakan untuk maksimum delapan loket yang dapat diatur sesuai kebutuhan, sehingga pada masa pendaftaran calon mahasiswa baru dapat diprioritaskan dengan mengatur sebagian besar loket untuk pendaftaran calon mahasiswa baru, demikian juga sebaliknya. 
4. Sistem antrian dilengkapi tombol untuk memilih kelompok mahasiswa dan memberikan nomor antrian yang sesuai.

5. Setiap loket dilengkapi dengan tombol yang harus ditekan oleh petugas setelah melayani mahasiswa agar sistem dapat mengenali loket yang kosong untuk melayani antrian berikutnya.

6. Sistem antrian dapat memberikan informasi nomor urut antrian yang sedang dilayani unit pendaftaran melalui monitor yang disediakan.

7. Sistem antrian dapat melakukan panggilan nomor urut dan nomor loket yang melayani melalui loudspeaker.

8. Jumlah nomor urut antrian maksimum 999.

9. Metode antrian yang digunakan adalah FIFO (first in first out).

\section{PENGUJIAN SISTEM}

Pengujian komunikasi serial dengan hyper terminal dilakukan dengan memberikan masukan dari tombol tekan, yang diproses menjadi data serial oleh mikrokontroler, kemudian RS-232 akan mengonversikan level tegangan data serial tersebut agar sesuai dengan level tegangan serial pada komputer. Data yang dikirim berupa karakter (ASCII), sehingga komputer langsung dapat membaca data tersebut sebagai karakter. Proses komunikasi ini dapat diuji menggunakan hyper terminal. Hasil pengujian diperlihatkan pada Tabel 2 dan penekanan tombol dengan menggunakan hyper terminal telah sesuai dengan perancangan.

Tabel 2. Hasil pengujian penekanan tombol

\begin{tabular}{|c|c|}
\hline Tombol yang ditekan & $\begin{array}{c}\text { Hasil tampilan pada } \\
\text { hyper terminal }\end{array}$ \\
\hline PB 1 & A \\
\hline PB 2 & B \\
\hline PB 3 & C \\
\hline PB 4 & D \\
\hline PB 5 & E \\
\hline PB 6 & F \\
\hline PB 7 & G \\
\hline PB 8 & H \\
\hline PB 9 & I \\
\hline PB 10 & J \\
\hline
\end{tabular}

Pada pengujian pencetakan nomor antrian terdapat dua buah tombol yang berfungsi untuk melakukan proses pencetakan nomor antrian, yaitu: tombol A yang berfungsi untuk melakukan pencetakan nomor antrian pelayanan pendaftaran mahasiswa lama, dan tombol B yang berfungsi untuk melakukan 
pencetakan nomor antrian pelayanan pendaftaran mahasiswa baru. Jika salah satu tombol tersebut ditekan, maka printer akan mencetak struk antrian. Struk antrian yang dicetak berisi informasi jenis pelayanan, tanggal, jam pencetakan, dan nomor antrian. Dari 30 kali pengujian, sistem telah berhasil memberikan keluaran pada cetakan struk sesuai dengan perancangan tanpa ada kesalahan.

Setiap loket dapat diatur jenis pelayanannya, untuk pelayanan mahasiswa lama maupun pelayanan mahasiswa baru sesuai kebutuhan, dengan mengklik button 'Atur Loket'. Setelah button 'Atur Loket' diklik maka akan muncul pilihan pada setiap loket berupa komponen radio button. Pilihan yang muncul berupa huruf 'A' dan 'B'. Huruf 'A' merupakan pilihan pelayanan mahasiswa lama, dan 'B' merupakan pilihan pelayanan mahasiswa baru. Apabila tidak dilakukan pengaturan loket, maka secara default loket 1 sampai loket 4 menjadi pelayanan mahasiswa lama, dan loket 5 sampai loket 8 menjadi pelayanan mahasiswa baru. Pengaturan loket diperlihatkan pada Gambar 6.

Setiap selesai memberikan pelayanan, petugas loket akan menekan tombol loket masingmasing untuk memanggil nomor antrian berikutnya, sesuai dengan jenis pelayanan yang telah diatur. Jika petugas loket yang menekan tombol adalah loket yang diatur menjadi pelayanan mahasiswa lama ('A'), maka sistem memanggil nomor antrian untuk pelayanan mahasiswa lama saja. Sebaliknya jika loket diatur menjadi pelayanan mahasiswa baru ('B'), maka sistem memanggil nomor antrian untuk pelayanan mahasiswa baru saja.

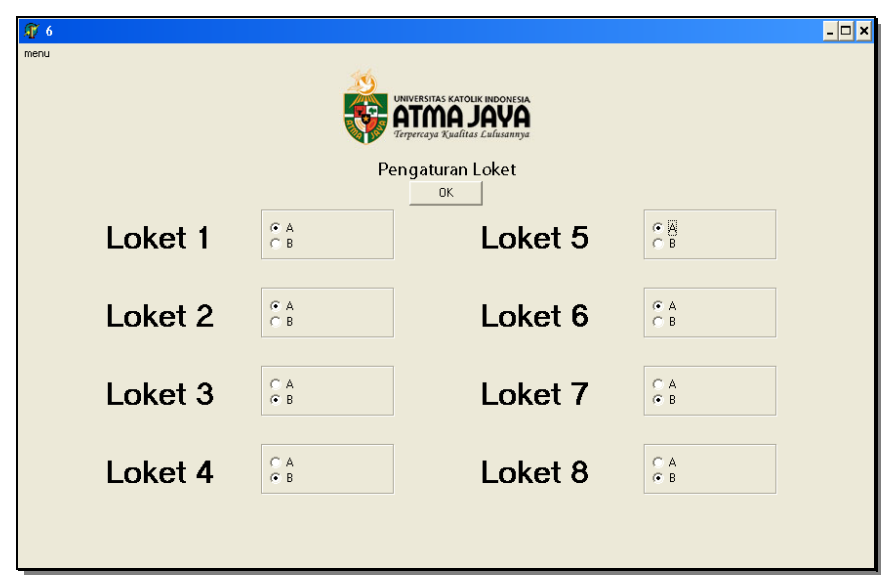

Gambar 6. Pengaturan loket

Nomor antrian yang dipanggil ditampilkan pada layar LCD seperti diperlihatkan pada Gambar 7. Saat tidak ada lagi antrian dan petugas menekan tombol maka sistem akan menampilkan '--', seperti diperlihatkan Gambar 8. Bersamaan dengan tampilan pada monitor LCD, sistem akan menghasilkan keluaran berupa suara lewat loudspeaker. Sebagai contoh jika tampilan pada monitor LCD Loket 1 menunjukan nomor antrian A2, maka sistem memanggil file suara yang sesuai sehingga akan dihasilkan keluaran suara sebagai berikut: "Nomor antrian A2, silakan ke loket 1". File suara yang dipanggil adalah, 'Nomor_antrian.wav', 'A.wav', '2.wav', 'Silakan_ke_loket.wav', dan '1.wav'. 
Hasil pengujian 30 kali panggilan nomor antrian dalam bentuk suara telah sesuai dengan perancangan dan tanpa ada kesalahan.

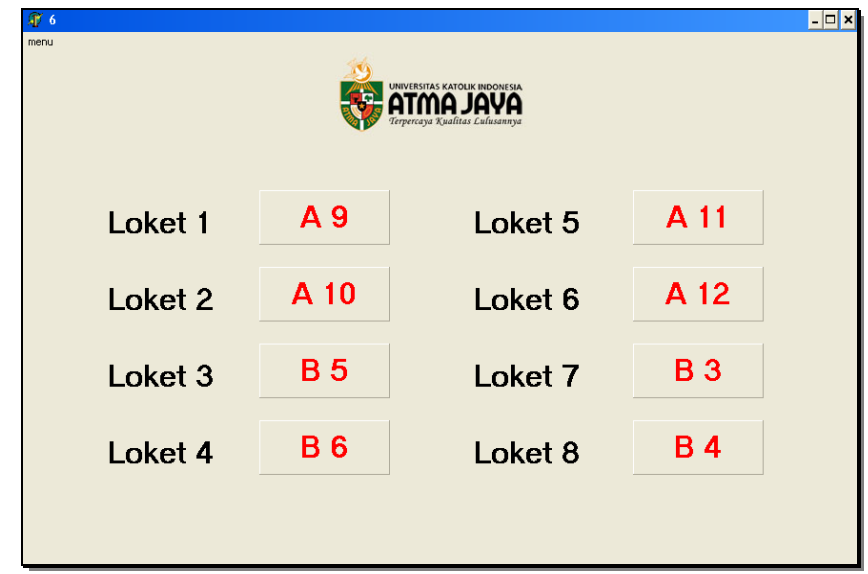

Gambar 7. Tampilan pada layar LCD saat ada antrian

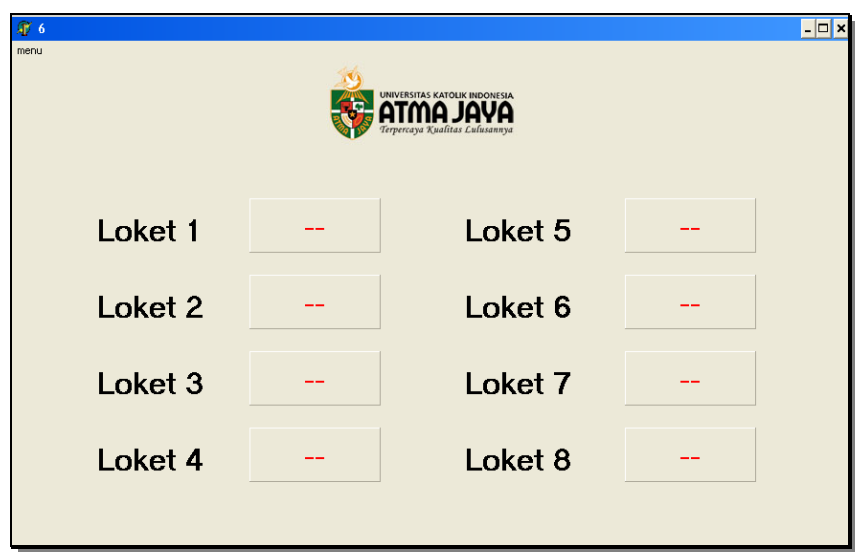

Gambar 8. Tampilan pada LCD saat tidak ada antrian

\section{KESIMPULAN}

Dari pembahasan perancangan dan pengujian yang telah dilakukan, maka dapat diambil kesimpulan sebagai berikut:

1. Komunikasi antara mikrokontroler dan komputer berjalan dengan baik.

2. Jenis pelayanan masing-masing loket dapat disesuaikan dengan kebutuhan kelompok mahasiswa yang akan dilayani di unit pendaftaran.

3. Sistem antrian dapat mencetak nomor antrian dan menampilkan nomor antrian di layar monitor LCD.

4. Sistem antrian dapat memberikan informasi nomor antrian dan nomor loket secara audio melalui loudspeaker. 
5. Dari pengujian secara keseluruhan, sistem antrian telah berfungsi sesuai perancangan.

\section{DAFTAR PUSTAKA}

[1] Andrianto, Heri. 2015. Pemrograman Mikrokontroler AVR ATMEGA16 Menggunakan Bahasa $C$ (Codevision AVR). Bandung: Penerbit Informatika.

[2] ATMEGA16 Datasheet. (http://www.alldata sheet.com, diakses 20 April 2019).

[3] Sumardi. 2013. Mikrokontroller, Belajar AVR Mulai dari Nol. Yogyakarta: Graha Ilmu.

[4] Stallings, William. 2016. Computer Oganization and Architecture, $10^{\text {th }}$ edition. New Jersey: Pearson Education.

[5] MAX232 Datasheet. (http://www.alldata sheet.com, diakses 20 April 2019).

[6] Barrow, John. Miller, Linda. Malan, Katherine. 2001. Introducing Delphi Programming, $4^{\text {th }}$ edition. Georgia: Oxford University Press. 